\title{
Natural History, Clinical Pattern, and Surgical Considerations of PNeumatosis Intestinalis
}

\author{
P. N. Khalil1,2,*, S. Huber-Wagner ${ }^{2,3}$, R. Ladurner ${ }^{1}$, A. Kleespies ${ }^{4}$, M. Siebeck ${ }^{1}$, W. Mutschler ${ }^{3}$, \\ K. Hallfeldt ${ }^{1}$, K.-G. Kanz ${ }^{2}$ \\ ${ }^{1}$ Division of General and Visceral Surgery, Department of Surgery, Downtown Medical Centre, \\ ${ }^{2}$ Division of Emergency Medicine, Department of Surgery, Downtown Medical Centre, \\ ${ }^{3}$ Division of Trauma Surgery, Department of Surgery, Downtown Medical Centre, \\ ${ }^{4}$ Department of Surgery, Großhadern Medical Centre, \\ Ludwig-Maximilians University, Munich, Germany
}

\begin{abstract}
Objective: Pneumatosis intestinalis has been increasingly detected in recent years with the more frequent use of computed tomography for abdominal imaging of the intestine. The underlying causes of the gas found during radiographic studies of the bowel wall can vary widely and different hypotheses regarding its pathophysiology have been postulated. Pneumatosis intestinalis often represents a benign condition and should not be considered an argument for surgery. However, it can also require life-threatening surgery in some cases, and this can be a difficult decision in some patients.

Methods: The spectrum of pneumatosis intestinalis is discussed here based on various computed tomographic and surgical findings in patients who presented at our University Medical Centre in 2003-2008. We have also systematically reviewed the literature to establish the current understanding of its aetiology and pathophysiology, and the possible clinical conditions associated with pneumatosis intestinalis and their management.
\end{abstract}

Results: Pneumatosis intestinalis is a primary radiographic finding. After its diagnosis, its specific pathogenesis should be ascertained because the appropriate therapy is related to the underlying cause of pneumatosis intestinalis, and this is sometimes difficult to define. Surgical treatment should be considered urgent in symptomatic patients presenting with an acute abdomen, signs of ischemia, or bowel obstruction. In asymptomatic patients with otherwise inconspicuous findings, the underlying disease should be treated first, rather than urgent exploratory surgery considered. Extensive and comprehensive information on the pathophysiology and clinical findings of pneumatosis intestinalis is provided here and is incorporated into a treatment algorithm.

Conclusions: The information presented here allows a better understanding of the radiographic diagnosis

\footnotetext{
* Supported by the Ludwig-Demling Research Found of the German Crohn's disease and ulcerative colitis Association (DCCV) by the Falk Foundation e.V., Freiburg, Germany and the Georg-Heberer Award for Surgical Research of the E. Chiles Foundation, Portland, Oregon, USA
}

and underlying aetiology of pneumatosis intestinalis, and may facilitate the decision-making process in this context, thus providing fast and adequate therapy to particular patients.

Key words: Pneumatosis intestinalis, gastrointestinal tract, gastrointestinal pathophysiology, abdominal emergencies, abdominal imaging

\section{INTRODUCTION}

Pneumatosis intestinalis is an imaging phenomenon representing the presence of gas in the bowel wall. It was first recognized by DuVernoi in 1730 during a cadaver dissection, and there have since been numerous reports of various underlying diseases [1-7]. Pneumatosis intestinalis was defined as a radiographic diagnosis by Lerner and Gazin as early as 1946 [8]. The clinical relevance of pneumatosis intestinalis varies widely and ranges from benign to life-threatening conditions depending on the underlying cause of pneumatosis intestinalis [4, 7]. The latter can entail high mortality if exploratory surgery is delayed $[4,6,7,9]$. The incidence of pneumatosis intestinalis is not yet precisely known, but it is increasingly reported because of the more frequent use of computed tomographic abdominal studies and recent improvements in imaging techniques $[4,7,9]$. Conversely, many new surgical procedures, medications, and medical treatments have contributed to the increase in this particular radiographic phenomenon. However, based on autopsy studies, its incidence in the general population has been estimated as three per 10,000 individuals [4]. Pneumatosis intestinalis can occur at any age, depending on the underlying cause. However, it is seen more frequently in older patients than in young adults or infants. The sex-specific distribution of this entity has not yet been described in the literature. So far, over 60 possible causative diseases have been proposed as contributing to gas accumulation within the bowel wall $[6,7]$. Most patients with a diagnosis of pneumatosis intestinalis can be managed without surgery by treating the causative disease. In 1998, Pear introduced a classification of the major pathogenic mechanisms causally involved in intramural gas formation, which included (i) bowel necrosis, (ii) mucosal disruption, (iii) increased mucosal permeabili- 
ty, and (iv) pulmonary disease [6]. Of these possible aetiologies, bowel necrosis appears to be the most common and life-threatening cause of intramural gas formation. In such cases, portal venous gas embolisation may be present because of a denuded mucosa [6]. Different types of gas formation occur, including bubbleand linear-shaped patterns, and some authors have attempted to assign these to one of the pathogenic causes discussed above, but with no confident results [4, 6 , 10-17]. It is imperative that the imaging finding of pneumatosis intestinalis is carefully correlated with the clinical findings of a physical examination, clinical history, and laboratory test results to determine which patients can be managed medically by treating the underlying disease and which will require emergency surgery. This decision-making process is critical and can be difficult because the origin of the gas is often unclear and the patient's symptoms can be volatile, presenting a major dilemma for the surgeon in charge. Here, we address these issues with respect to the nature and pathophysiology of pneumatosis intestinalis and extend our knowledge by reviewing the current literature. Although descriptive radiological reviews and various case reports of pneumatosis intestinalis are available, including case-related therapies and outcomes, there is a lack of information with regard to an acceptable structured treatment-directed process $[4,6,7]$. Therefore, based on our own experiences at the Department of Surgery at the Ludwig-Maximilians University, Munich, and a critical review of the literature, we provide a treatment algorithm for the better and faster management of patients with a radiographic diagnosis of pneumatosis intestinalis.

\section{Material And Methods}

A systematic literature search was performed using PubMed, with the key words pneumatosis intestinalis and mucosal gas, in conjunction with aetiology, pathophysiology, risk factors, and surgery. We also searched the in-hospital database for patients with diagnoses of pneumatosis intestinalis presenting in 2003-2008 and reviewed the patients' histories, therapies, courses, and outcomes.

\section{Results}

We present the different typical computed tomographic and intra-operative findings of patients treated for pneumatosis intestinalis at the Division of General and Visceral Surgery, Department of Surgery, LudwigMaximilians University, Munich. Representative operative and computed tomographic findings were selected and are given in Figure 1-4. The present selection demonstrates the wide range of diseases associated with pneumatosis intestinalis. Moreover, extended information was collected with regard to the nature and pathophysiology of this primary radiographic diagnosis with a PubMed database search, which was used as the basis for the decision-making process presented here. The in-hospital review of patients with a diagnosis of pneumatosis intestinalis, the diagnostic process, and their therapies and outcomes have been incorporated into the algorithm presented here.

\subsection{Pathophysiology}

Pneumatosis intestinalis is defined as the presence of gas in the bowel wall $[4,6,7]$. The gas inclusion can occur to various extents in the small or large bowel, or even in both. The intramural gas may appear cystic, bubbly, curvilinear, or linear [6]. A pneumoperitoneum, pneumoretroperitoneum, or even portal venous gas inclusions can also be present [6]. Different theories have been proposed to explain the nature and pathophysiology of intramural gas [2, 4, 6, 7, 18-26]. However, the exact cause of the gas remains unknown [4]. In 1998, Pear classified the causes of pneumatosis intestinalis into four essential pathologies: bowel necrosis, mucosal disruption, increased mucosal permeability, and pulmonary disease [6]. Two main theories of the pathophysiology of gas formation in the bowel wall have been proposed in recent years, based on a mechanical or a bacterial cause $[4,26]$. The mechanical theory hypothesizes that the gas moves into the bowel wall from either the intestinal lumen or the lungs via the mediastinum by different mechanisms, leading to an increase in pressure. The bacterial theory proposes that the gas is produced by gas-forming bacteria that enter the mucosal barrier through mucosal rents or increased mucosal permeability and produce the gas within the bowel wall $[4,26]$. In contrast to those theories, St. Peter and co-workers have suggested that the pathophysiology of pneumatosis intestinalis convincingly reflects the origin of the gas, postulating the three major sources: (i) intraluminal gastrointestinal gas, (ii) bacterial gas production, and (iii) pulmonary gas. These are summarized below [7].

\section{(i) Intraluminal gas}

An increase in intraluminal pressure, which may occur with blunt trauma, pyloric stenosis in infants, or bowel obstruction, can cause pneumatosis intestinalis, whether or not the mucosal barrier is intact. However, at least some degree of associated mucosal injury is most likely when blunt trauma precedes pneumatosis intestinalis. Here, enhanced gut permeability to gas may be induced by defects in the mucosa, the immune barrier, or both. A reduced mucosal barrier and normal luminal pressure are seen, for instance, in congenital or acquired immunodeficiency, and in patients receiving immunosuppressive therapy. In these patients, bacterial intrusion or gas diffusion into the bowel wall is more likely to occur.

\section{(ii) Bacterial gas}

In recent years, several authors have suggested that bacterial gas production is a relevant factor in pneumatosis intestinalis, and this is supported by reports of the disappearance of the gas after antimicrobial drug therapy. Bacterial gas can accumulate after the direct invasion of the bowel wall by bacteria or by their alteration of the intraluminal gas content. Gas-producing bacteria reach the intramural compartment because of an increase in intramural pressure, mucosal injury, or a combination of these factors. This possible mechanism is supported by the theory of counterperfusion supersaturation, whereby the intraluminal bacterially produced hydrogen tension exceeds the nitrogen tension 
in the blood, causing a hydrogen diffusion gradient towards the submucosal vessels. This theory may also explain the pneumatosis observed near blood vessels along the mesenteric border.

\section{(iii) Pulmonary gas}

Another possible source of pneumatosis intestinalis is pulmonary gas. It has been postulated that alveolar rupture can result in the movement of air along vascular channels in the mediastinum, tracking caudally via the retroperitoneum and to the mesentery of the bowel. Pulmonary gas migration to the subserosal layer of the intestine has been observed in patients with pulmonary disease. It is more likely that the gas migrates along these vessels in these patients than that it has a transmural origin. Conversely, many of these patients show no signs of interstitial lung or mesenteric emphysema, prompting the theory that in this population, the gas is caused by an increase in intra-abdominal pressure resulting from pulmonary obstruction, together with a reduced barrier function caused by corticoid therapy.

\subsection{Clinical Spectrum}

Pneumatosis intestinalis is a radiographic phenomenon produced by underlying diseases or conditions, which can vary widely $[4,6,7]$. It has been shown that the pattern or extent of pneumatosis intestinalis does not necessarily correlate with the severity of the symptoms or underlying disease [7, 25, 27]. Mesenteric ischemia, bowel obstruction, and bowel necrosis represent the most life-threatening causes of pneumatosis intestinalis $[4,7,9,28]$. In this context, it must be noted that proven pneumatosis intestinalis in conjunction with a serum lactic acid level exceeding 2 $\mathrm{mmol} / \mathrm{L}$ entails a high rate of fatal outcomes, of over $80 \%$ [9, 29]. However, pneumatosis intestinalis may also be the result of numerous non-ischemic and non-obstructive conditions, most of which are apparently not associated with unfavourable outcomes $[4,7$, $17,30]$. Thus, in recent years, over 60 causative diseases and conditions have been identified in this context [7]. We must be aware that a number of causes can be both benign and life threatening, depending on the circumstances $[4,7]$. It is often challenging in clinical practice to distinguish those patients who definitively require surgery and those who can be observed or managed conservatively with the appropriate treatment of the underlying disease without any need for exploratory surgery.

Pneumatosis intestinalis can originate from pulmonary, systemic, or intestinal bowel diseases and conditions. Moreover, numerous iatrogenic causes have been described in the literature. Other major causes, including medication-associated or even postoperative aetiologies, have been described. Vascular diseases or their associated diseases and conditions contribute substantially to the life-threatening causes of pneumatosis intestinalis, as discussed above. Finally, idiopathic forms of pneumatosis intestinalis are described in literature and account for about $15 \%$ of all cases. Table 1 summarizes the major documented diseases

Table 1. Disease and conditions associated with pneumatosis intestinalis.

\begin{tabular}{lcc}
\hline Pulmonary & Autoimmune and systemic & Drug induced \\
Asthma & Lupus variants & Corticosteroids \\
COPD & Polymyositis & Chemotherapeutic agents \\
Emphysema & Dermatomyositis & Lactulose \\
Bronchitis & Polyarteritis nodosa & Sorbitol \\
Pulmonary fibrosis & Scleroderma & Glucosidase inhibitor \\
Cystic fibrosis & Sacroidose & Chloral hydrate \\
& Celiac sprue & \\
Gastrointestinal & & Organtransplantation \\
IBD & Infectious & Bone marrow e.g. for leukemia \\
Diverticulitis & HIV and AIDS & Kidney, Lung, Liver \\
Colitis incl. toxic variants and & Virus (CMV, rota-, adeno-, varicella- & Graft versus host \\
clostridium difficile & zoster virus) & \\
Enteritis incl. bacteriel, virus, & Candida albicans & \\
fungal and atypical forms & Mycobacterium tuberculosis & \\
Toxic megacolon & Iatrogenic & Vascular \\
Appendicitis & Blunt abdominal trauma & Mesenteric vascular disease \\
Intestinal obstruction, pseudo- & Endoscopy & Intestinal infarction and ischemia \\
obstruction, volvulus & Postsurgical intestinal anastomosis & \\
Bowel stenosis incl. pyloric & Jenunoileal bypass & Idiopathic (primary) \\
stenosis & Barium enema & \\
Adynamic ileus & Enteric tube placement & \\
Carcinoma & PEEP ventilation & \\
Peptic ulcer & & \\
Celiac sprue & & \\
\hline
\end{tabular}

COPD, chronic obstructive pulmonary disease; IBD, Crohn's disease and ulcerative colitis; HIV and AIDS, human immunodificiency virus and acquired immunodeficiency syndrome; positive end-exparatory pressure, PEEP 

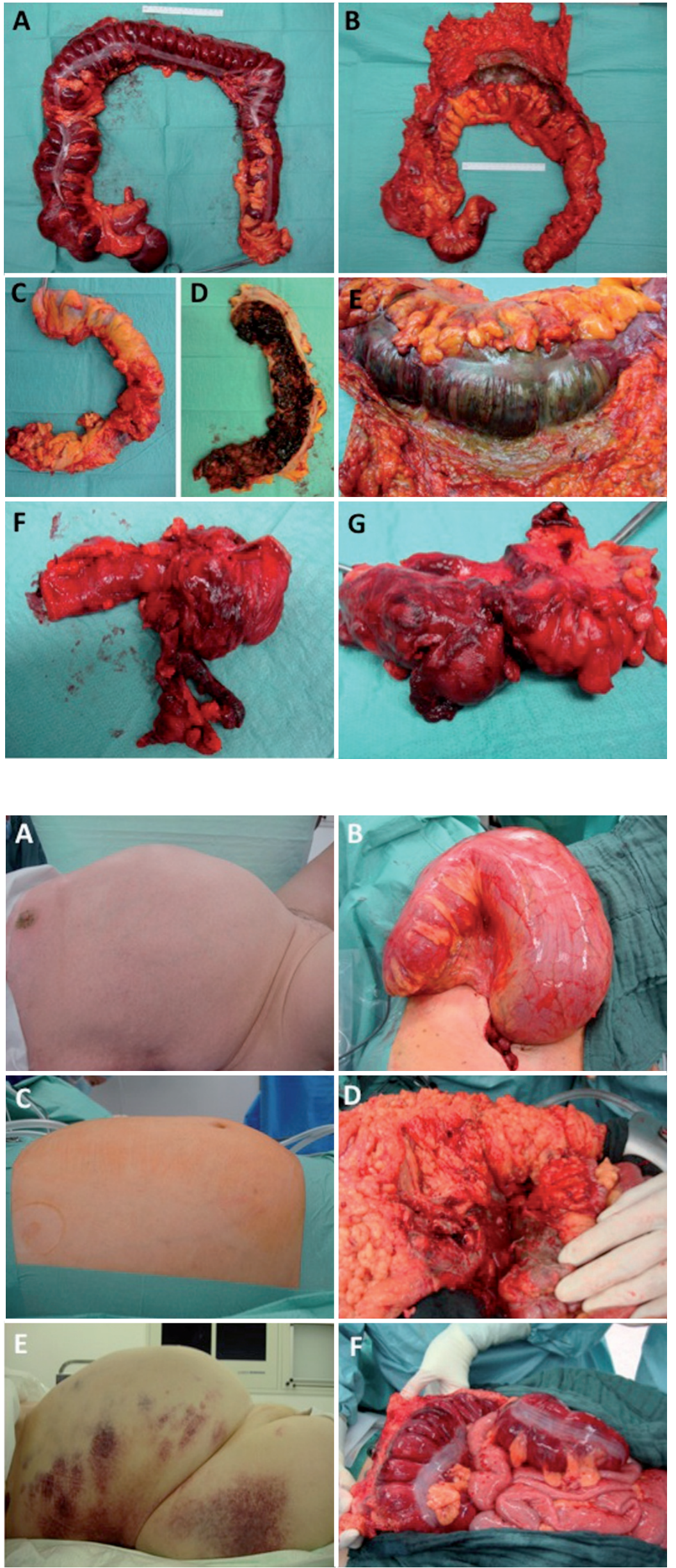

Fig. 1. Intraoperative causes of pneumatosis intestinals related to the large bowel. Toxic megacolon coursed by Clostridium difficile infection (A), Necrosis of the colon (colon transversum) with gangrenous bowel wall by mesenterial embolism (B and $\mathrm{E}$ ), severe bleeding caused by ulcerative colitis ( $\mathrm{C}$ and D), necrotic appendicitis ( $F$ and $G$ ).
Fig. 3. Clinical pictures of the abdomen in patients with diagnosis of pneumatosis intestinalis and operative findings. Volvulus of the colon sigmoideum (A and B), blunt abdominal trauma (C and $\mathrm{D})$, and toxic megacolon $(\mathrm{E}$ and $\mathrm{F})$. 


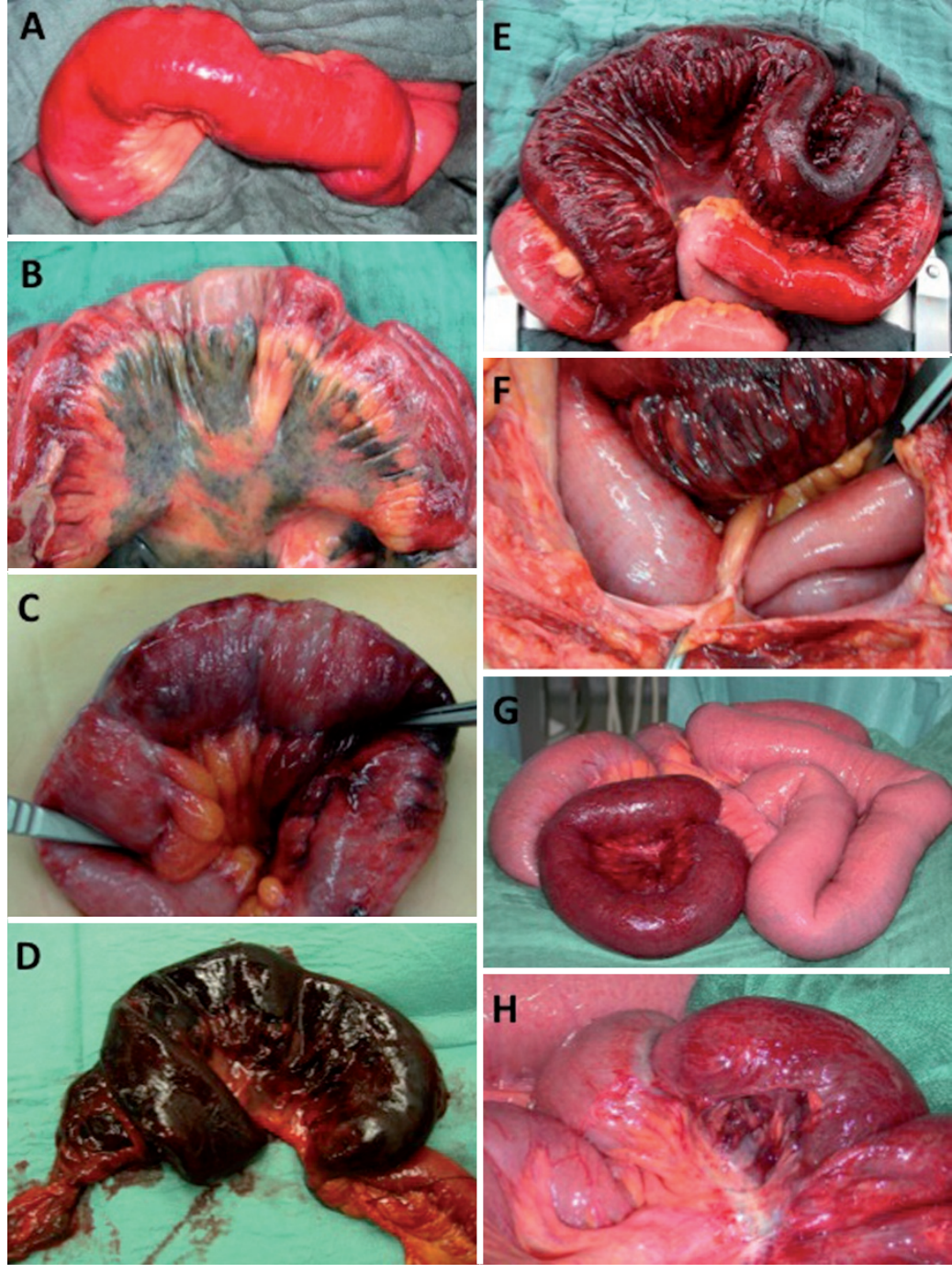

Fig. 2. Intraoperative causes of pneumatosis intestinalis related to the small bowel. Limited early small bowel ischemia (A), extended hemorrhagic small bowel infarction (B), small bowel ischemia with partial necrosis (C), gangrenous ileum segment small bowel caused by ischemia (D), necrotic ileum segment (E) due to a bridle stricture (F), ischemic ileum segment $(G)$ and detailed view of $G$ showing a constriction mark as its cause $(\mathrm{H})$. and conditions associated with pneumatosis intestinalis [4-7, 31-66]. Some causes of pneumatosis intestinalis can be classified as both benign and life-threatening conditions [4].

The benign causes of pneumatosis intestinalis usually result in only mild or even no abdominal symptoms. Patients usually display cardiopulmonary stability, with lactate levels within the normal limits, and do not present with septic signs or respiratory acidosis [9]. In these patients, there is often no computed tomographic abnormalities other than the diagnosis of pneumatosis. In contrast, patients with life-threatening causes of pneumatosis intestinalis usually display peritoneal symptoms. A retrospective analysis of 919 documented cases of pneumatosis intestinalis identified diarrhoea, bloody stools, abdominal pain, constipation, weight loss, and tenesmus as the most common related symptoms, in descending order [30]. Another retrospective analysis of a 10 -year period at a single institution found, with a multivariable analysis, that age $\geq 60$ years, the presence of emesis, and a white blood cell count of $>12 \mathrm{c} / \mathrm{mm}^{3}$ were independently associated with surgical management, and that pre-existing sepsis correlated with a higher risk of death in this context [9].

\subsection{Diagnosis AND Therapy}

The diagnosis of pneumatosis intestinalis is made, in general, by computed tomography or plain radiography of the abdomen, although computed tomography is the most sensitive imaging modality [4]. After the identification of pneumatosis intestinalis, a prompt further evaluation of the patient should be made. This should include concomitant radiographic findings, such as wall thickening, the presence of portal venous gas, and free intra-abdominal air. The morphological signs of gas formation in the bowel wall can be classified as: (i) cystic or bubbly, if consisting mainly of isolated bubbles of air; or (ii) curvilinear or linear, if consisting of continuous bands of air in the bowel wall [6, 28]. Linear or curvilinear pneumatosis is thought to be more characteristic of bowel ischemia, and of the presence of portal venous gas, than is bubbly pneumatosis, which may be more often benign, although this cannot be considered a rule $[4,7,9-12,14,17]$. The radiographic location and appearance of the gas may be helpful, but they do not represent pathognomic features for the diagnosis of its origin. A strong indicator of the presence of mesenteric infarction or segmental ischemia, and therefore an indication for 

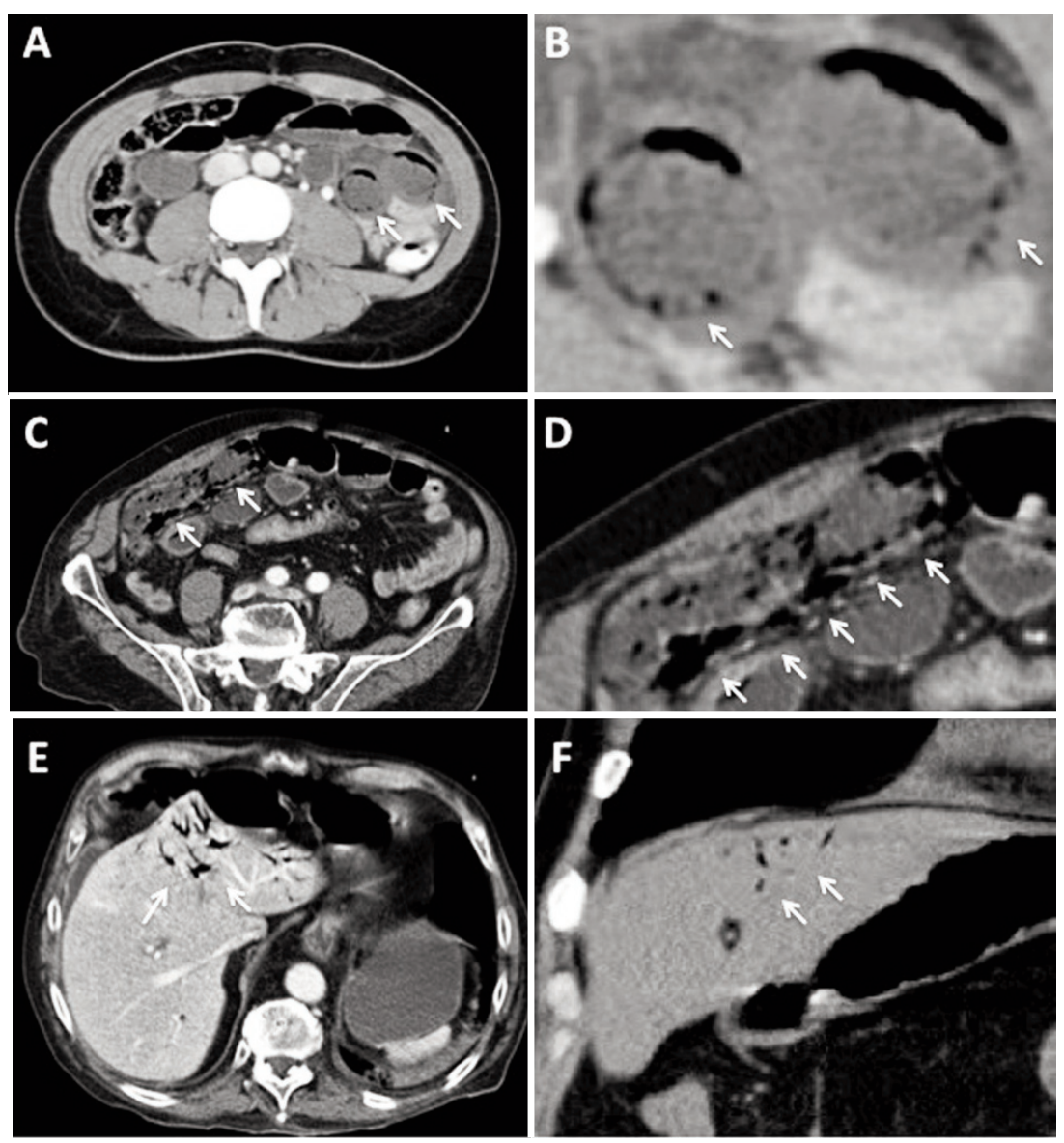

Fig. 4. Representativ computed tomographic findings of pneumatosis intestinalis (A and $\mathrm{C}), \mathrm{B}$ is a magnifiation of $\mathrm{A}$ and $\mathrm{D}$ a magnification of $\mathrm{C}$. Examples of portal venous gas leading to intrahepatic gas formation ( $\mathrm{E}$ and $\mathrm{F}$ ). The white arrows indicates the gas bubbles.

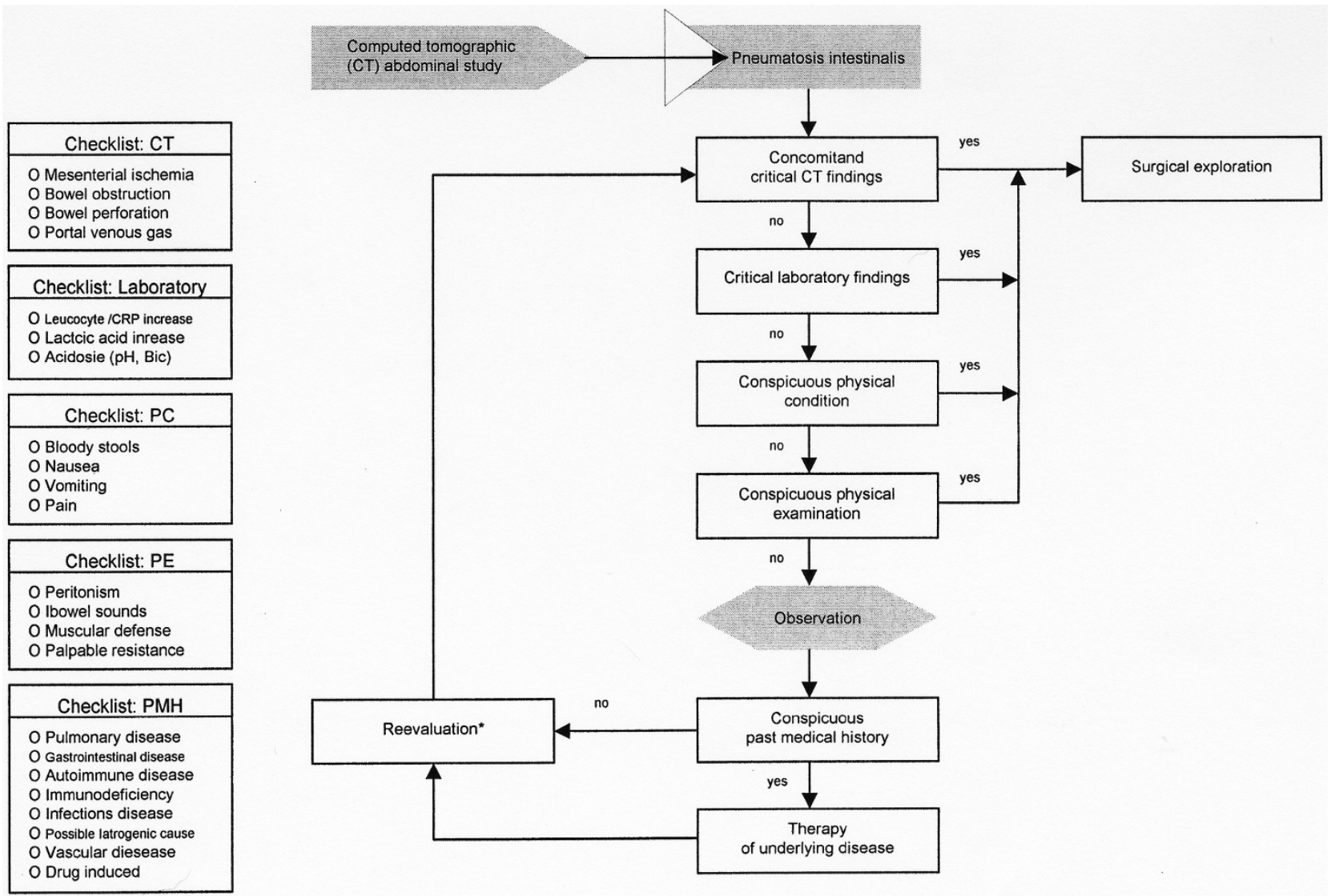

Fig. 5. Decision making algorithm after diagnosis of pneumatosis intestinalis. CT (computed tomography), PC (physical condition), PE (physical examination), PMH (past medical history). ${ }^{*}$ In some cases reevaluation can be done by ultrasound instead of CT scan. 
emergency exploratory surgery, is the association of pneumatosis intestinalis with portomesenteric venous gas $[4,6,9,10,21]$. However, pneumatosis and portomesenteric venous gas can also occur together in a variety of non-ischemic conditions that are not associated with an unfavourable outcome $[10,12,16,67$, 68]. Signs of bowel perforation or peritonitis also warrant emergency surgery. However, in asymptomatic patients with radiographic signs of pneumatosis intestinalis but no concomitant signs of bowel obstruction or free peritoneal air, emergency exploratory surgery is not indicated $[2,4,6,7,9,17,50]$. It is most often appropriate that these patients are observed and treated conservatively.

The therapeutic management of pneumatosis intestinalis must focus on the underlying disease rather than on the radiographic sign itself $[4,6,7]$. Thus, the medical history of the patient and his/her current medications should be evaluated carefully to guide further decision processes. In this context, it is advisable to enquire about the different categories of associated conditions, such as pulmonary, gastrointestinal, autoimmune, infectious, pulmonary, iatrogenic, drug-induced, or transplantation-related conditions, as shown in Figure 1. Thus, the survey should determine any types of pulmonary disease, recent gastrointestinal intervention or surgery, inflammatory bowel disease, history of gastrointestinal complaints such as gastroenteritis symptoms, autoimmune disease, infectious disease, or any type of vascular disease. Queries about currently used medications should be included in the interview, especially any cytotoxic, immunsuppressive, or corticosteroid drugs, and the use of lactulose, sorbitol, or glucosidase inhibitors. The core temperature should be measured by rectal probe and the patient asked to relate any recent history of fever or shivering, or current emesis. During the physical examination, the extent of the abdominal complaint should be evaluated. The examination must include bowel sounds, any palpable resistance indicative of an abdominal mass, and signs of peritonism. The heart rate and blood pressure must be documented, together with the respiration rate and volume, and oxygen supplied as needed. Routine laboratory tests should be made, including a blood count, test for coagulation, electrolytes, serum creatinine, C-reactive protein, and lactic acid, and liver and pancreatic indices. The decisionmaking process is the culmination of the findings obtained during the survey described here, and will include three possible treatment options: (i) emergency surgery, (ii) observation, followed by later re-evaluation, and (iii) medical treatment of the underlying disease. Figure 5 summarizes the queries and the results obtained, and provides support for each particular decision level with a formal treatment algorithm.

\section{Discussion}

This paper provides detailed information on our current understanding of pneumatosis intestinalis with regard to its natural history, clinical spectrum, and medical management. We searched the current literature and reviewed the patients evaluated for pneumatosis intestinalis within the last five years at our Department of Surgery. There are numerous reports, especially case reports and some structured reviews, in the literature dealing with pneumatosis intestinalis, and the question can be raised whether there is a need for the present paper [31-66]. However, there is a lack of information regarding the medical management of particular patients presenting with pneumatosis intestinalis. Moreover, current reviews usually focus on the findings of apparative diagnostics, e.g., computed tomography and plain radiography from a radiological point of view, rather than on the provision of support for clinical management [4-7]. To the best of our knowledge, only a few available papers address these issues [9, 29, 69]. It must be stressed that the underlying cause of pneumatosis intestinalis is the most important factor, in conjunction with its clinical presentation and laboratory results, in the management of patients with radiographically demonstrable pneumatosis intestinalis [4, $9,7,28$. Three possible decisions can be made from a surgical point of view: (i) does the patient require emergency surgery? (ii) can the patient be simply observed, with later re-evaluation? or (iii) can the patient be managed conservatively by treating the underlying disease? This decision process is crucial because any delay will probably affect the patient's outcome. It is clear from the literature that the underlying disease not only determines this outcome but also the length of time available until exploratory surgery is performed. Greenstein and co-workers observed in their recent study a trend to a lower mortality rate in patients receiving operative therapy with a delay of $<6 \mathrm{~h}$ after the diagnosis of pneumatosis intestinalis [9].

We have described the different pathogenic theories of pneumatosis intestinalis and its associated clinical features. However, pneumatosis intestinalis remains incompletely understood and seems to be a multifactorial entity. In general, two theories have been proposed, the mechanical and the bacterial, which can be further divided by detail. It is most likely that pneumatosis intestinalis is a combination of both causes. We must be aware that the pattern or extent of pneumatosis intestinalis does not necessarily correlate with the severity of the symptoms or the underlying disease $[7,27]$. There is a long and confusing list of disorders and conditions associated in the literature with pneumatosis intestinalis. Therefore, to minimise confusion, it is important to sort these into the eight major categories: (i) pulmonary, (ii) gastrointestinal, (iii) autoimmune and systemic, (iv) infectious, (v) iatrogenic, (vi) drug induced, (vii) post-transplantational, and (viii) idiopathic.

Life-threatening conditions are most often associated with mesenteric ischemia, bowel necrosis, or bowel obstruction. These patients often present with signs of sepsis and symptoms of shock. An acute abdomen is often the predominant clinical feature and the outcome for these patients is the most unfavourable among patients with pneumatosis intstinalis. In immunocompromised patients, those receiving steroids, those at early presentation, or multimorbid patients, the diagnosis can sometimes be difficult because only discrete symptoms may be present. In these patients, further radiographic signs, like bowel-wall thickening or the whirlpool sign and the presence of concomitant 
portal venous gas or free intra-abdominal air, should also be taken in account, together with their laboratory results. The combination of pneumatosis intestinalis and portal venous gas is associated with bowel ischemia in about $70 \%$ of cases $[14,16]$. In this context, Greenstein and co-workers showed with multivariable analysis that an age of $\geq 60$ years, the presence of emesis, and a white blood count of $>12 \mathrm{c} / \mathrm{mm}^{3}$ are independent factors associated with surgical management in patients with pneumatosis intestinalis [9]. Moreover, a serum lactate concentration of $\geq 2.0$ $\mathrm{mmol} / \mathrm{L}$ is associated with an unfavourable outcome, as is the presence of sepsis, hypotension, metabolic acidosis, or a thickened bowel wall. Although the presence of portal venous gas in combination with pneumatosis intestinalis can occur in benign conditions, its presence is an indication for surgery if iatrogenic causes can be excluded, because bowel ischemia is most likely and a delay in exploratory surgery will worsen the patient's outcome $[9,10]$. When non-surgical management is undertaken initially, the patient should be subsequently re-evaluated, with exploratory surgery performed if he/she does not respond to medical therapy or the condition worsens [7].

We have here provided a treatment algorithm for patients with a diagnosis of pneumatosis intestinalis, based on our own experiences with pneumatosis intestinalis and the findings of a literature search. Rather than being a strict instruction guide, this structured algorithm supports the decision-making process. It may help to reduce the rate of patients with benign forms of pneumatosis unnecessarily subjected to exploratory surgery and reduce the delay in surgical therapy for those patients who would profit from early surgical intervention $[9,17]$.

\section{REFERENCES}

1. DuVernoi JG. Anatomische Beobachtungen der unter der äußeren und inneren Haut der Gederme eingeschlossenen Luft. Phys Med Abbhand Acad Wissensch in Petersb 1783: 182.

2. Boerner RM, Fried DB, Warshauer DM, Isaacs K. Pneumatosis intestinalis. Two case reports and a retrospective review of the literature from 1885 to 1995 . Dig Dis Sci 1996; 41: 2272-2285.

3. Heng Y, Schuffler MD, Haggitt RC, Rohrmann CA. Pneumatosis intestinalis: a review. Am J Gastroenterol 1995; 90: 1747-1758.

4. Ho LM, Paulson EK, Thompson WM. Pneumatosis intestinalis in the adult: benign to life threatening causes. Am J Roentgenol 2007; 188: 1604-1613.

5. Koss LG. Abdominal gas cysts (pneumatosis cystoides intestinorum hominis): an analysis with a report of a case and a critical review of the literature. AMA Arch Pathol 1952; 53: 523-549.

6. Pear BL. Pneumatosis intestinalis: a review. Radiology 1998; 207: 13-19.

7. St Peter SD, Abbas MA, Kelly KA. The spectrum of pneumatosis intestinalis. Arch Surg 2003; 138: 68-75.

8. Lerner HH, Gazin Al. Pneumatosis intestinalis: its roentgenologic diagnosis. Am J Roentgenol 1946; 56: 464-469.

9. Greenstein AJ, Nguyen SQ, Berlin A, Corona J, Lee J, Wong E, Factor SH, Divino CM. Pneumatosis intestinalis in adults: management, surgical indications, and risk factors for mortality. J Gastrointest Surg 2007; 11: 12681274.
10. Wiesner W, Mortele KJ, Glickman JN, Ji M, Ros PR. Pneumatosis intestinalis and portomesenteric venous gas in intestinal ischemia: correlation of ct findings with severity of ischemia and clinical outcome. Am J Roentgenol 2001; 177: 1319-1323.

11. Liebman PR, Patten MT, Manny J, Benfield JR, Hechtman HB. Hepatic-portal venous gas in adults: etiology, pathophysiology and clinical significance. Ann Surg 1978; 187: 281-287.

12. Griffiths DM, Gough MH. Gas in the portal hepatic veins. Br J Surg 1986; 73: 172-176.

13. Hong JJ, Gadaleta D, Rossi P, Esquivel J, Davis JM. Portal vein gas, a changing clinical entity: report of 7 patients and review of the literature. Arch Surg 1997; 132: 10711075.

14. Paran H, Epstein T, Gutman M, Shapiro Feinberg M, Tissin R,. Mesenteric and portal vein gas: ocmuterized tomography findings and clinical significance. Dig Surg 2003; 20: 127-132.

15. Kernagis LY, Levine MS, Jacobs JE. Pneumatosis intestinalis in patients with ischemia: correlation of CT findings with viability of the bowel. Am J Roentgenol 2003; 180: 733-736.

16. Wiesner W, Mortele KJ, Glickman JN, Ji H, Ros PR. Portal-venous gas unrelated to mesenteric ischemia. Eur Radiol 2002; 12: 1432 -143.

17. Liu DM, Torreggiani WC, Rowan K, Nicolaou S. Benign pneumatosis intestinalis: a cause of massive pneumoperitoneum in the adult. Can J Emerg Med 2003; 5: 416-420.

18. Yale CE, Balish E, Wu JP. The bacterial etiology of pneumatosis cystoides intestinalis. Arch Surg 1974; 109: 8994.

19. Olmsted WW, Madewell JE. Pneumatosis cystoides intestinalis: pathophysiologic explanation of the roentgenographic signs. Gastrointest Radiol 1976; 1: 177-181.

20. Wolfe JN, Evans WA. Gas in portal veins of liver in infants: roentgenographic demonstration with postmortem anatomical correlation. Am J Roentgenol 1955; 74: 486489.

21. Susman N, Senturia HR. Gas embolization of the portal venous system. Am J Roentgenol 1960; 83: 847-850.

22. Keyting WS, McCarver RR, KovarikJL, Daywill AL. Pneumatosis intestinalis: a new concept. Radiology 1961; 76: 733-741.

23. Doub HP, Shea JJ. Pneumatosis cystoides intestinalis. JAMA 1960; 172: 1238-1242.

24. Elliott GB, Elliott KA. The roentgenologic pathology of so-called pneumatosis cystoides intestinalis. Am J Roentgenol 1963; 89: 720-729.

25. Borns PF, Johnston TA. Indolent pneumatosis of the bowel wall associated with immune suppressive therapy. Ann Radiol 1973; 16: 163-166.

26. Galandiuk S, Fazio VW. Pneumatosis cystoides intestinalis: a review of the literature. Dis Colon Rectum 1986; $29: 358-363$.

27. Feczko PJ, Mezwa DG, Farah MC, White BD. Clinical significance of pneumatosis of the bowel wall. Radiographics 1992; 12: 1069-1078.

28. Pai HJ, Wang CS, Hsieh CC, Wang WK, Yang BY. Pneumatosis intestinalis: a rare manifestation of acute appendicitis. doi: 10.1016/j.jemermed.2007.02.058

29. Hawn MT, Canon CL, Lockhart ME, et al. Serum lactic acid determines the outcomes of CT diagnosis of pneumatosis of the gastrointestinal tract. Am Surg 2004; 70: 19-23; discussion 23-24.

30. Jamart J. Pneumatosis cystoides intestinalis. A statistical study of 919 cases. Acta Heoato Gastroenterol 1979; 26: 419-422.

31. Kelly BS Jr, Meyers P, Choe KA, Hurst J, Luchette FA. Traumatic pneumatosis cystoides intestinalis with portal venous air embolism. J Trauma 1997; 42: 112-114. 
32. Waring JP, Manne RK, Wadas DD, Sanowski RA. Mucosal pseudolipomatosis: an air pressure-related colonoscopy complication. Gastrointest Endosc 1989; 35: 93-94.

33. Doolas A, Breyer RH, Franklin JL. Pneumatosis cystoides intestinalis following jejunoileal bypass. Am J Gastroenterol 1979; 72: 271-275.

34. Lester PD, Budge AF, Barnes JC, Kirks DR. Gastric emphysema in infants with hypertrophic pyloric stenosis. AJR Am J Roentgenol 1978; 131: 421-423.

35. Gupta A. Interstitial gastric emphysema in a child with duodenal stenosis. Br J Radiol 1977; 50: 222-224.

36. Eggli KD, Loyer E, Anderson K. Neonatal pneumatosis cystoides intestinalis caused by volvulus of the mid intestine. Arch Dis Child. 1989; 64: 1189-1190.

37. Gillon J, Holt S, Sircus W. Pneumatosis coli and sigmoid volvulus: a report of 4 cases. Br J Surg 1979; 66: 802-805.

38. Horiuchi A, Akamatsu T, Mukawa K, Ochi Y, Arakura N, Kiyosawa K. Case report: pneumatosis cystoides intestinalis associated with post-surgical bowel anastomosis: a report of three cases and review of the Japanese literature. J Gastroenterol Hepatol 1998; 13: 534-537.

39. Seto T, Koide N, Taniuchi N, Yamada T, Hamaguchi M, Goto S. Pneumatosis cystoides intestinalis complicating carcinoma of the small intestine. Am J Surg 2001; 182: 287-288.

40. Stuart M. Pneumatosis coli complicating carcinoma of the colon: report of a case. Dis Colon Rectum 1984; 27: 257 259.

41. Cho KC, Simmons MZ, Baker SR, Cappell MS. Spontaneous dissection of air into the transverse mesocolon during double-contrast barium enema. Gastrointest Radiol 1990; 15: 76-77.

42. Galandiuk S, Fazio VW, Petras RE. Pneumatosis cystoides intestinalis in Crohn's disease: report of two cases. Dis Colon Rectum 1985; 28: 951-956.

43. Silliman CC, Haase GM, Strain JD, et al. Indications for surgical intervention for gastrointestinal emergencies in children receiving chemotherapy. Cancer 1994; 74: 203216.

44. Laing TJ. Gastrointestinal vasculitis and pneumatosis intestinalis due to systemic lupus erythematosus: successful treatment with pulse intravenous cyclophosphamide. Am J Med 1988; 85: 555-558.

45. Sackier JM, Smith EJ, Wood CB. Cystic pneumatosis in coeliac disease. Gut 1988; 29: 852-855.

46. Kuroda T, Ohfuchi Y, Hirose S, Nakano M, Gejyo F, Arakawa M. Pneumatosis cystoides intestinalis in a patient with polymyositis. Clin Rheumatol 2001; 20: 49-52.

47. Karp DR, Kantor OS, Halverson JD, Atkinson JP. Successful management of catastrophic gastrointestinal involvement in polyarteritis nodosa. Arthritis Rheum 1988; 31: 683-687.

48. Kreiss C, Forohar F, Smithline AE, Brandt LJ. Pneumatosis intestinalis complicating C. difficile pseudomembranous colitis. Am J Gastroenterol 1999; 94: 2560-2561.

49. Cunnion KM. Pneumatosis intestinalis in pediatric acquired immunodeficiency syndrome. Pediatr Infect Dis J 1998; 17: 355-356.

50. Fenton LZ, Buonomo C. Benign pneumatosis in children. Pediatr Radiol 2000; 30: 786-793.

51. Bohler A, Speich R, Russi EW, Meyenberger C, Weder W. Pneumatosis intestinalis and active cytomegaloviral infection after lung transplantation. Chest 1995; 107: 582583.

52. Day DL, Ramsay NK, Letourneau JG. Pneumatosis intestinalis after bone marrow transplantation. AJR Am J Roentgenol 1988; 151: 85-87.

53. Doub HP, Shea JJ. Pneumatosis cystoides intestinalis. JAMA 1960; 172: 1238-1242.
54. Keyting WS, McCarver RR, Kavarik JL. Pneumatosis intestinalis: a new concept. Radiology 1961; 76: 733-741.

55. Hashimoto S, Saitoh H, Wada K, et al. Pneumatosis cystoides intestinalis after chemotherapy for hematological malignancies: report of 4 cases. Intern Med 1995; 34: 212215.

56. Murphy BJ, Weinfeld A. Innocuous pneumatosis intestinalis of the right colon in renal transplant recipients: report of three cases. Dis Colon Rectum 1987; 30: 816-819.

57. Goodman RA, Riley III TR. Lactulose-induced pneumatosis intestinalis and pneumoperitoneum. Dig Dis Sci 2001; 46: 2549-2553.

58. Zimmerman AL, Gupta JK, Ingegno AP. Pneumatosis coli following treatment with lactulose. N Y State J Med 1979; 79: 1896-1899.

59. Hayakawa T, Yoneshima M, Abe T, Nomura G. Pneumatosis cystoides intestinalis after treatment with an alpha-glucosidase inhibitor. Diabetes Care 1999; 22: 366367.

60. Duncan B, Barton LL, Eicher ML, Chmielarczyk VT, Erdman SH, Hulett RL. Medication-induced pneumatosis intestinalis. Pediatrics 1997; 99: 633-636.

61. Marigold JH. Pneumatosis cystoides coli and chloral hydrate. Gut 1998; 42: 899-900.

62. Berdon W, Grossman H, Baker D, et al. Necrotizing enterocolitis in the premature infant. Radiology 1964; 83: 879-887.

63. Meihoff WE, Hirschfield JS, Kern F Jr. Small intestinal scleroderma with malabsorption and pneumatosis cystoides intestinalis: report of three cases. JAMA 1968; 204 : 854-858.

64. Schulenburg A, Herold C, Eisenhuber E, et al. Pneumocystis cystoides intestinalis with pneumoperitoneum and pneumoretroperitoneum in a patient with extensive chronic graft-versus-host disease. Bone Marrow Transplant 1999; 24: 331-333.

65. Luks FI, Chung MA, Brandt ML, et al. Pneumatosis and pneumoperitoneum in chronic idiopathic intestinal pseudoobstruction. J Pediatr Surg 1991; 26: 1384-1386.

66. Stollman NH, Lee KF. Primary pneumatosis cystoides intestinalis. Gastrointest Endosc 2000; 52: 233.

67. Schulze CG, Blum U, Haag K. Hepatic portal venous gas: imaging modalities and clinical significance. Acta Radiol 1995; 36: 377-380.

68. Liebmann PR, Patten MT, Maay J, Benfield JR, Hechtman HB. Hepatic-portal venous gas in adults: etiology pathophysiology and clinical significance. Ann Surg 1978; 187: 281-287

69. Knechtle SJ, Davidoff AM, Rice RP. Pneumatosis intestinalis. Surgical management and clinical outcome. Ann Surg 1990; 212: 160-165.

Received: May 3, 2009 / Accepted: May 7, 2009

Address for correspondence:

Priv.-Doz. Dr. Philipe N. Khalil

Division of General and Visceral Surgery

Department of Surgery

Downtown Medical Centre

Ludwug-Maximilians University

Nußbaumstr. 20

80336 Munich

Germany

Tel.: $\quad+49-89 / 5160-2511$

Fax: +49-89/5160-4722

E-mail: philipe.khalil@med.uni-muenchen.de 